\title{
TEST ENVIRONMENT FOR HIGH- PERFORMANCE PRECISION ASSEMBLY - DEVELOPMENT AND PRELIMINARY TESTS
}

\author{
Timo Prusi, Riku Heikkilä, Jani Uusitalo, Reijo Tuokko \\ Tampere University of Technology, Institute of Production Engineering, Robotics and \\ Automation Laboratory, P.O. BOX 589, FIN-33101 Tampere, Finland, Tel +358331154487 , \\ Fax+358331152753, timo.prusi@tut.fi, riku.heikkila@tut.fi, jani.uusitalo@ut.fi, and \\ reijo.tuokko@tut.fi
}

Abstract: This paper presents a test environment enabling the study of factors affecting on the success of a robotic precision assembly work cycle. The developed testing environment measures forces and torques occurring during the assembly, and uses a system based on machine vision to measure the repeatability of work piece positioning. The testing environment is capable of producing exactly known artificial positioning errors in four degrees-offreedom to simulate errors in work-piece positioning accuracy. The testing environment also measures the total duration of the robot work cycle as well as the durations of all essential phases of the work cycle. The testing environment is best suited for light assembly operations and has measurement ranges of $\pm 36 \mathrm{~N}$ and $\pm 0.5 \mathrm{Nm}$ and the vision system has a field-of-view of 6 $\mathrm{mm}$.

The latter part of this paper presents the results of the research done in order to find out how some selected factors affect the assembly forces of robotic assembly. These factors include work piece and process parameters such as work piece material and design (chamfered/straight), positioning tolerances, and robot insertion motion speed.

Key words: Assembly force, assembly process testing, work cycle time, positioning errors 


\section{INTRODUCTION}

Assembly is widely accepted as the most time-consuming part of manufacturing process for industrial goods, and especially in electronics production (Rampersad 1994, Lane \& Stranahan 1986, Myrup Andreasen et al 1988).

The productivity of assembly processes and assembly equipment should be maximized in order to provide companies with the best possible return for their investments. The productivity of assembly equipment can be maximized by minimizing assembly work cycle durations and assembly equipment down time. In order to minimize work cycle durations and equipment down time, it is necessary to know what are the causes of faults or errors during assembly - or in other words the factors that affect the success of a precision assembly work cycle. Table 1 summarizes some of these factors that can be divided into four main groups: factors dealing with part, with equipment, with environment, and with the assembly task itself. Factors dealing with the equipment are further divided into three groups of factors dealing with robot, with gripper, and with feeder. Most of them were found in previous researches such as Rampersaad (1994), Linderstram (1995), and Rathmill (1985), but some result from the discussions at our laboratory.

Table 1. Possible factors affecting the success of an assembly work cycle

\begin{tabular}{|c|c|}
\hline & Factor \\
\hline \multirow{5}{*}{ Part } & $\begin{array}{l}\text { The shape, size, symmetry, geometry and weight (also affects the } \\
\text { dynamic behavior of the robot) }\end{array}$ \\
\hline & Material; stiffness, vulnerability, elasticity, "slipperiness" \\
\hline & $\begin{array}{l}\text { Design; chamfers and other guiding surfaces, self-alignment, } \\
\text { hidden features, catering for grippers, tolerance }\end{array}$ \\
\hline & $\begin{array}{l}\text { Physical appearance errors such as, dimensional, geometrical, } \\
\text { surface, and ruts }\end{array}$ \\
\hline & Other; (surface)quality, temperature \\
\hline \multirow{3}{*}{ Robot } & Repeatability, accuracy \\
\hline & $\begin{array}{l}\text { Dynamic behavior; speed, acceleration/deceleration (affected by } \\
\text { gripper and part weight) }\end{array}$ \\
\hline & Design; lifting capacity, stiffness, compliance \\
\hline \multirow{2}{*}{ Gripper } & Weight (affects the dynamic behavior of the robot) \\
\hline & Type, accuracy, gripping force, actuation \\
\hline Feeder & Accuracy, repeatability, reliability \\
\hline \multirow{3}{*}{ Environment } & $\begin{array}{l}\text { Contamination, humidity (small particles may jam the peg in the } \\
\text { hole) }\end{array}$ \\
\hline & (Electrical) interference \\
\hline & Temperature \\
\hline \multirow[t]{2}{*}{ Task } & Assembly direction, manner of approach, stability of the (base)part \\
\hline & $\begin{array}{l}\text { Type of assembly, cycle time, needed positional accuracy, number } \\
\text { of different components }\end{array}$ \\
\hline
\end{tabular}




\begin{tabular}{|l|l|}
\hline & Factor \\
\hline & $\begin{array}{l}\text { Collisions, impact while extracting part at pick-up, impact when } \\
\text { starting insertion }\end{array}$ \\
\hline \multirow{2}{*}{ Other } & Active control; force and/or vision \\
\cline { 2 - 2 } & Remote center compliance units (RCC-unit) \\
\hline
\end{tabular}

\section{TEST ENVIRONMENT}

In order to study the effects of various factors on the success of a precision assembly work cycle, a novel test environment was developed. The developed test environment is portable, compact in size, and it was designed to be easily applicable to practical cases without major modifications to assembly equipment. It can measure work piece positioning repeatability, forces and torques acting. The forces and moments acting during the insertion phase of the work cycle are measured with a 6 degree-of-freedom force and torque sensor having a measurement range of $\pm 36 \mathrm{~N}$ and $\pm 0.5 \mathrm{Nm}$ and resolution of $2.0^{*} 10^{\wedge}-3 \mathrm{~N}$ and $2.5^{*} 10^{\wedge}-5 \mathrm{Nm}$ (Ati 2005). The F/T-sensor is located directly under the assembly location. Both the F/T-sensor and assembly location are assembled on top of precision stages enabling $X Y$ movements and rotation and tilt adjustments of the assembly location thus enabling accurately know positioning errors to be made to the assembly location during the insertion of the work piece. Figure 1 shows the test environment and a small scara-type robot (Mitsubishi $\mathrm{RP}-1 \mathrm{H}$ ) used in the tests.

In Figure 1 the robot is in the starting position directly above the assembly location. From there, the robot moves above the pick-up location on the left in Figure 1, moves down, grasps the part, moves first up and then back to the starting position. From there starts the actual downward insertion movement during which the forces and torques are measured and recorded. After inserting the part, the robot opens the gripper and moves up back to the starting position. Finally, the work piece positioning repeatability is measured with a machine vision based system.

Figure 2 shows the system used to measure work piece positioning repeatability. It consists of a standard machine vision sensor (Cognex InSight 2000), a partially telecentric lens (Edmund Optics), three prisms, and a purpose-design stand. In the system, a right-angle prism (prism 1) divides the camera image vertically into two equally sized parts. The left-hand side of the image turns $90^{\circ}$ to left in the image-dividing prism 1, and the righthand side continues directly. Two more right-angle prisms bend the two 


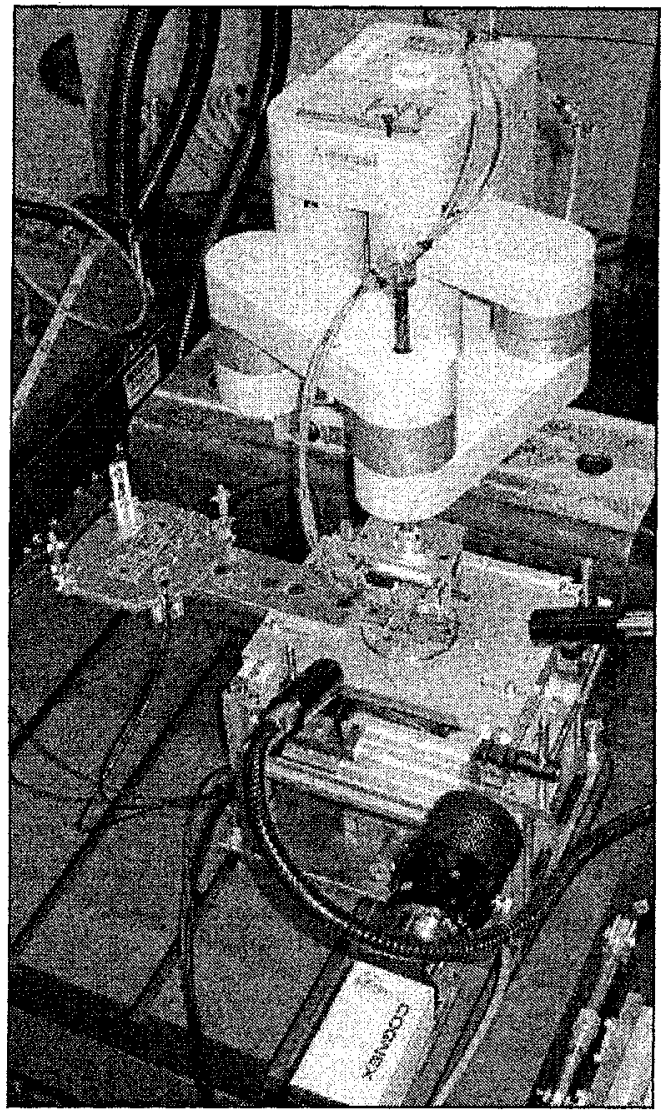

separate optical paths towards the center of the testing environment and the work object.

This set-up enables measuring work piece positioning repeatability in five degreesof-freedom: $\quad \mathrm{XYZ}$ movements and rotations about $\mathrm{X}$ - and $\mathrm{Y}$-axes. The horizontal field-of-view of this system is approximately $6 \mathrm{~mm}$ in total thus giving field-of-view of $3 \mathrm{~mm}$ per half-image. The measurements with this set-up have repeatability of less than $10 \mu \mathrm{m}$. (Prusi 2003)

Figure 1. The test environment and a small scara-type robot.

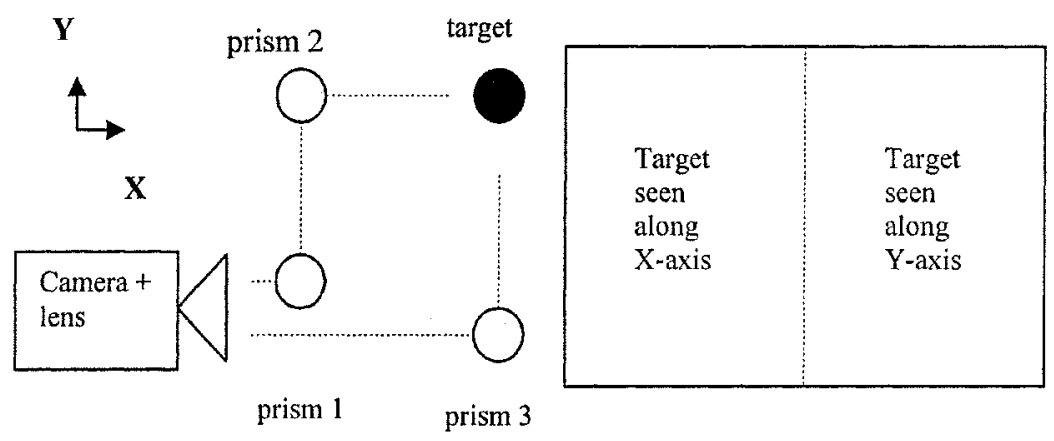

Figure 2. The principle arrangement of the system used to measure work piece positioning repeatability and a resulting image. 
Work cycle duration is measured on PC. In addition to the total work cycle duration, the test environment also measures and records the durations of selected phases of the work cycle. These phases are: 1) from the start of the robot work cycle to the moment robot has picked the part, 2) from the start to the moment the actual work piece insertion starts, and 3) the duration of the actual insertion. The moment when the robot has picked the part is detected with optical sensors assembled around the pick-up location. The start and the end of the insertion phase are detected from the F/Tmeasurements, namely the first moment when any of the six F/Tcomponents exceeds a specified threshold and the moment when all of the six F/T-components are again below the threshold.

Total robot work cycle duration
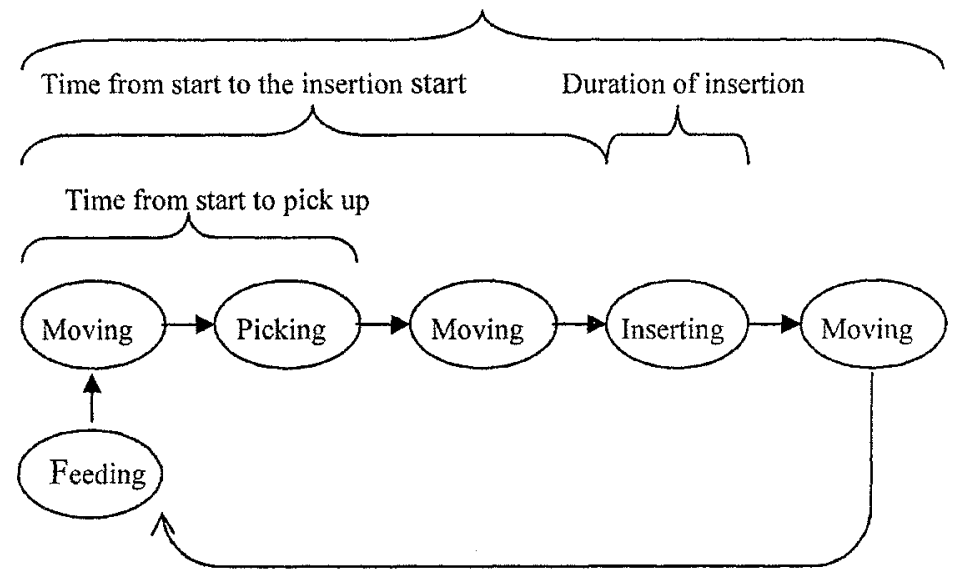

Figure 3. Phases of a typical robot assembly work cycle. Figure shows also the phases of the work cycle whose durations are measured.

The operation of the test environment is controlled with a purpose made software running on standard office-PC and Windows 2000. The software not only records the measured data but it also acts as an interface for the operator. With the software, the operator sets up the test parameters, monitors the measurements, and also analyses the measurement data. The measured data is saved in text-format and is therefore easy to import to other applications such as Microsoft Excel for more detailed analysis.

A more detailed description of the testing environment can be found in (Prusi, 2003). 


\section{TESTS}

In order to validate the operation of the testing environment and to study the effects of some work piece and process parameters, a series of tests were run where the robot performed a simple peg-in-a-hole assembly operation. The peg-in-a-hole task is a rather artificial case but it was used because of its simplicity. However, the environment itself does not limit the product to be assembled and studied. From the performed test runs, we can study the effects of the following factors:

- The design of the hole (chamfered / straight).

- The material of the plate where the hole is (aluminum / plastic).

- The design of the steel peg (rounded/straight).

- The effect of the use of an RCC-unit (remote center compliance) from CCMOP (CCMOP 2005) having compliance only in X and Y directions.

Next we will present and discuss some findings from the performed tests. Figure 4 shows measured forces in the direction of the insertion movement (negative $Z$ ) during the insertion phase. In our tests, the insertion phase took approximately $150 \mathrm{~ms}$. Forces were recorded at $10 \mathrm{~ms}$ intervals. As figure 4 shows, without chamfers the insertion force has its maximum very early when the edge of the straight peg hits the top surface of the plate before the peg slides into the hole. On the other hand, with rounded peg and chamfered hole, the peg slides more easily into the hole and the maximum force occurs when the chamfer ends and the actual, quite tight hole starts. From there on, the forces are quite similar.

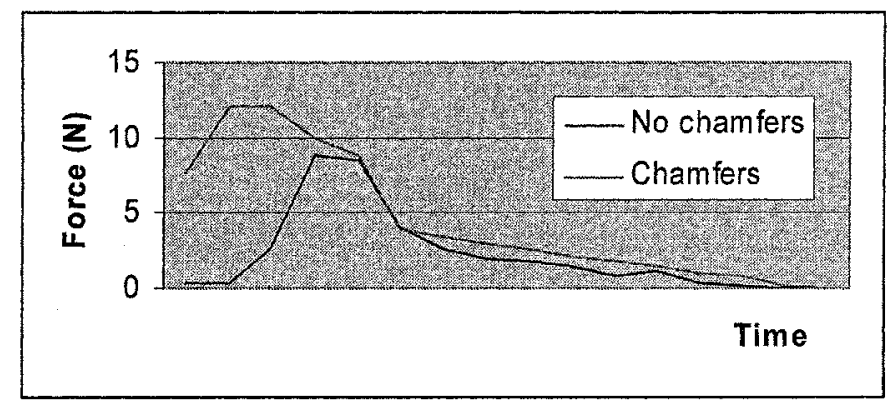

Figure 4. Typical insertion forces with and without hole and peg chamfers.

Figure 5 shows the effect of the rounding in the peg. The graphs show maximum forces measured with varying positioning error of the hole. The upper graph shows the forces when both the hole and the peg were straight whereas in the lower the peg was rounded. With straight peg and large positioning errors, the edge of the peg collides with the edge of the hole and does not slide into the hole. Therefore, only $0.20 \mathrm{~mm}$ error could be 
measured. With the rounded peg, on the other hand, the rounding guides the peg into the hole and the deflection of the robot Z-axis allows even $1 \mathrm{~mm}$ positioning error.
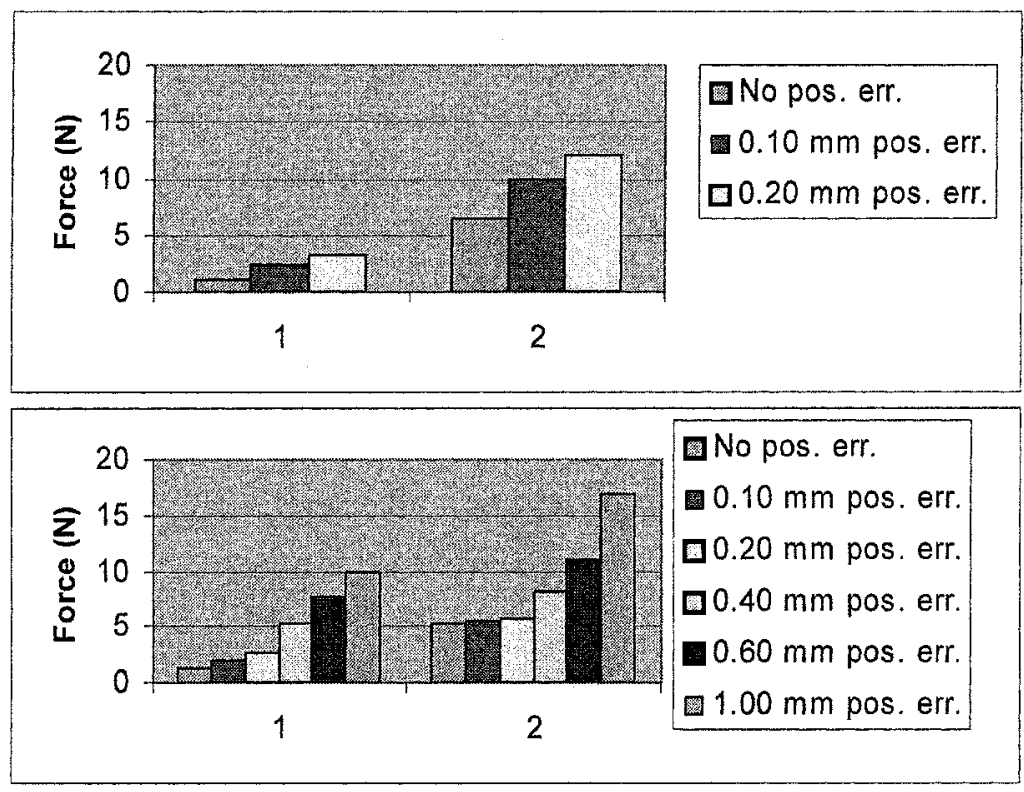

Figure 5. Average maximum forces of tests run with varying positioning error in positive Xdirection. In the upper graph, both the peg and the hole were straight whereas in the lover the peg was rounded and the hole straight. The leftmost cluster shows forces in negative Xdirection and the rightmost in negative $\mathrm{Z}$-direction (the direction of the insertion movement).

In addition to forces, the test environment also measures the durations of selected phases of the work cycle (fig. 3). These measurements can be used to maximize the performance of the assembly equipment by minimizing the work cycle duration but still confirming that the forces do not exceed safe values. For example, we did some tests with different robot insertion motion speeds and found that in that case, $30 \%$ of maximum speed was the highest safe speed and with higher speeds, the initial impact forces were too high.

\section{CONCLUSIONS}

In this paper, we have presented a test environment for high-performance precision assembly. The test environment has proven to be a suitable tool for measuring and analyzing a typical robotic pick-and-place work cycle. It can 
be used to study the effects of various work piece and assembly process parameters. It could also be used to confirm the operation of real assembly equipment: are the assembly forces within safe limits, is the equipment as productive as possible or could some movements be faster without compromising the probability of the assembly task to succeed, etc.

The performed tests show, for example, that the rounding and chamfer used do not necessarily reduce the force needed to insert the peg into the hole but they do reduce the initial contact force and therefore make the insertion more likely to succeed.

\section{ACKNOWLEDGEMENTS}

The authors would like to express their gratitude to Mr. Heikki Junttari, Mr. Riku Lampinen, and Mr. Juha Veittiaho for performing the measurements and for helping with the analysis of the results.

\section{REFERENCES}

1. Ati Industrial Automation, Nano $43 \mathrm{~F} / \mathrm{T}$ sensor, product information. http://www.atiia.com/library/documents/ATI_FT_Sensor_Catalog_2005.pdf (referenced June 29th, 2005)

2. CCMOP, product information of a remote compliance center unit $\mathrm{CH} 50$, http://www.ccmop.com/ $\rightarrow$ Products $\rightarrow$ Robot Peripheral Tools (referenced June $16^{\text {th }}$, 2005).

3. Edmund Optics, product information of a partially telecentric video lens, http://www.edmundoptics.com/onlinecatalog/displayproduct.cfm?productID=1963\&searc $h=1$ (referenced June $27^{\text {th }}, 2005$ )

4. Lane, Jack D.; Stranahan, Judy D. (editors). 1986. Automated Assembly. Dearborn, USA, Society of Manufacturing Engineers. 452 pages.

5. Linderstram, Charlotta. 1995. On Monitoring Interactions for Error Detection in Robotic Assembly, PhD Thesis. Linköping, Linköping University, Department of Mechanical Engineering. 108 pages.

6. Myrup Andreasen, Mogens; Kähler, Steen; Lund, Thomas. 1988. Desing for Assembly, $2^{\text {nd }}$ Edition. Bedford, UK, IFS Publications. 212 pages.

7. Prusi, Timo 2003. Test environment for high-performance precision assembly. Master of Science Thesis. Tampere: Tampere University of Technology, Automation Department. 88 pages.

8. Rampersad, Hubert K. 1994. Integrated and Simultaneous Design for Robotic Assembly. West Sussex, England, John Wiley \& Sons. 212 pages.

9. Rathmill, Keith (editor). 1985. Robotic assembly. Bedford, UK, IFS Publications. 365 pages. 